\title{
Unusual Large Ethmoidal Osteoma with Orbital Extension
}

\section{Adouly T*, Adnane C, Belfaquir L, Rouadi S, Abada R, Roubal M and Mahtar M}

Department of ENT, 20 Août hospital. Ibn Rochd university hospital, Casablanca, Morocco

*Corresponding author: Adouly T, Department of ENT, 20 Aout hospital, Ibn Rochd university hospital, Casablanca, Morocco, E-mail: adouly.taoufik@gmail.com

Citation: Adouly T, Adnane C, Belfaquir L, Rouadi S, Abada R, et al. (2014) Unusual Large Ethmoidal Osteoma with Orbital Extension. J Case Rep Stud 2(6): 602. doi: 10.15744/2348-9820.2.302

Received Date: November 06, 2014 Accepted Date: December 02, 2014 Published Date: December 04, 2014

\begin{abstract}
Large osteomas of the fronto-ethmoidal cavities are very rare benign tumors. Headache and ocular signs are the most common symptoms. Imaging allows the diagnosis. Treatment of ethmoid sinus osteoma is surgical. One case with orbital extension is reported and discussed. A 30 years-old male; complaining of swelling of themedial angle of the right eye. Computed tomography showed a right ethmoidal process with orbital extension. The tumor was removed through an external ethmoidectomy. Histological examination confirmed diagnosis. The patient's follow-up for the last 12 months was normal. The clinical characteristics and treatment of this disease remain controversial; this case report highlights the epidemiological, clinical, radiological, treatment and histological aspects of this rare disease.
\end{abstract}

Keywords: Osteoma; Benign Paranasal Pinuses Tumors; Orbit; Surgery

\section{Introduction}

Paranasal sinus osteomas are benign bone tumors. They are usually asymptomatic and found incidentally on 3\% of sinus computed tomography scans [1]. They grow slowly, became symptomatic and occasionally cause complications depending on their anatomical site [1]. Osteoma with a diameter $>30 \mathrm{~mm}$ or weighing $>110 \mathrm{~g}$ is considered a "large" or "giant" osteoma and then surgery is required [2]. They are still more infrequent, and lead to intracranial and or orbital complications [3]. We report a rare case of a large orbito-ethmoidal osteoma, in order to analyze the epidemiological; clinical; radiological; treatment and histological aspects of this disease because the clinical characteristics and treatment remain controversial.

\section{Report case}

A 30-year-old male, presented in our ENT department; with a 2 years history of hard swelling of the medial angle of the right eye. The patient complained of headache with pain around the right eye. He was in good health, and her medical history revealed recurrent rhino sinusitis. Clinical examination showed swelling in the right inner canthal area, and right painful proptosis. A significant limitation in adduction of the right globe was evident. Visual function was preserved and visual acuity was measured as $10 / 10$ in each eye. A systemic examination was unremarkable. Nasal endoscopic examination found no nasal polyposis. Computed tomography revealed a multilobulated mass, highly calcified with osseous density, measuring $30 \mathrm{~mm} \times 24 \mathrm{~mm} \times 21 \mathrm{~mm}$ arising from right ethmoidal sinus with extension laterally in to the right orbital (Figure 1 and 2).

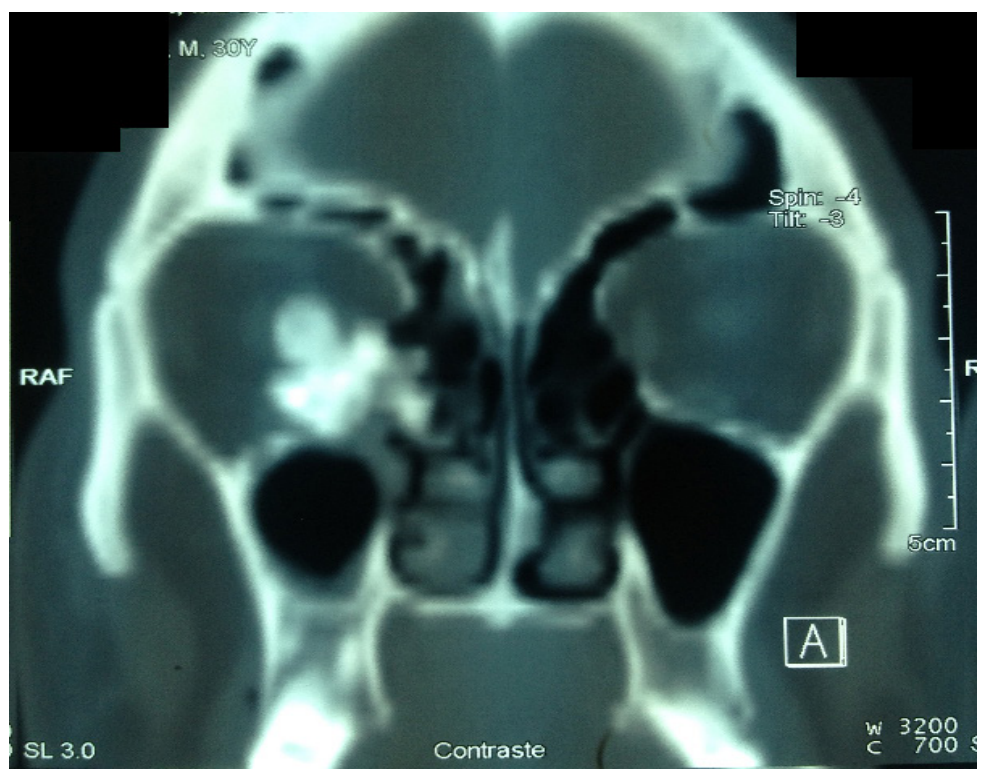

Figure 1: Coronal CT revealed a large calcified mass in the right ethmoidal sinus with orbital extension 


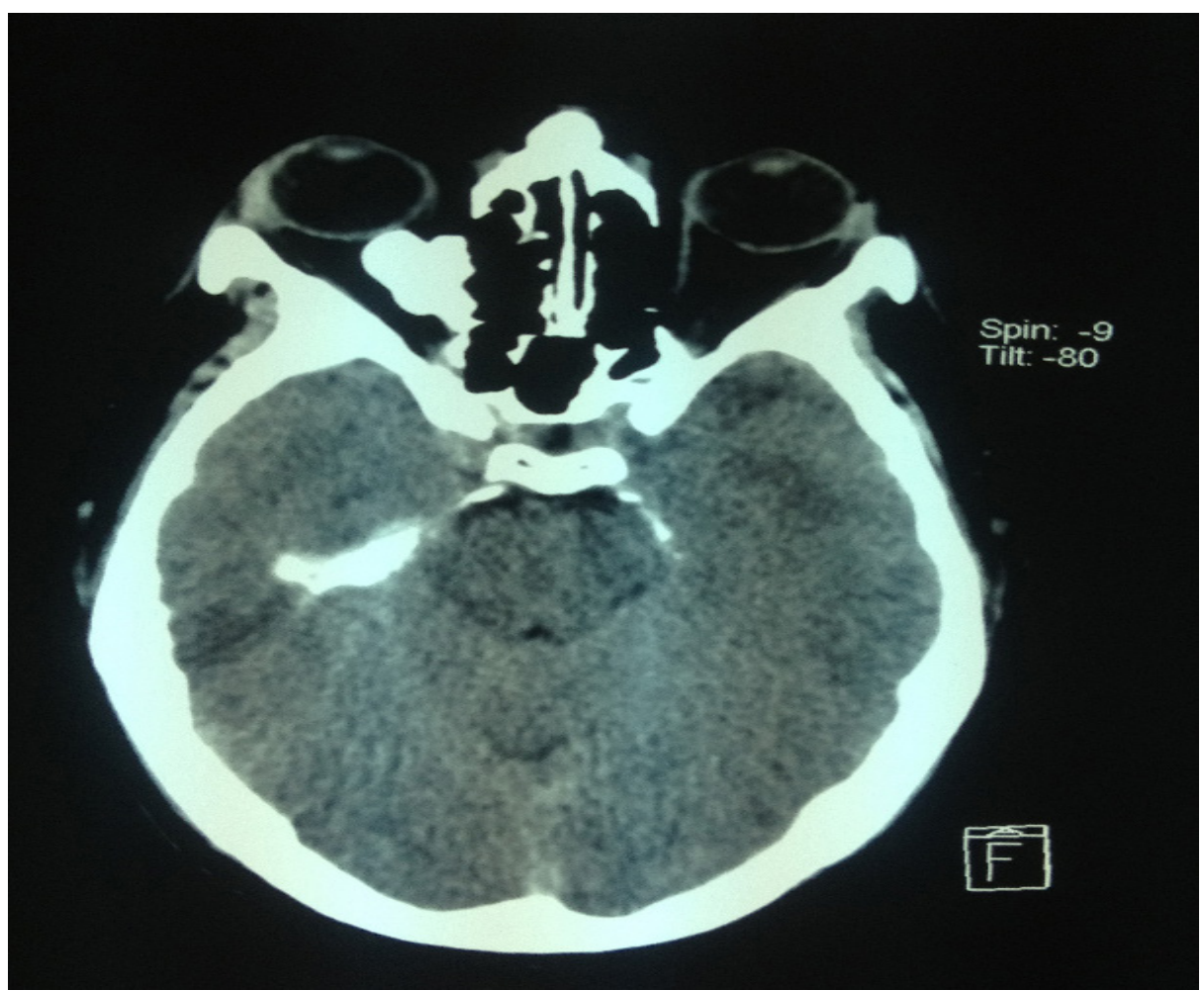

Figure 2: Axial CT revealed a large mass in the right anterior ethmoidal sinus with orbital extension

Proctoscopy showed no abnormal findings and exclude Gardner's syndrome. The diagnosis of a large orbito-ethmoidal osteoma was suspected. An external approach (external ethmoidectomy) was planned. The incision was Lynch-Howarth along the superomedial quadrant or region of the orbit. Dissection was continued posteriorly. Osteoma was resected en bloc using a drill and curette. The periorbital layer was preserved, and then the reconstruction wasn't necessary. The drainage is established by widening the bone at the most dependent part in communication with the nasal cavity. The postoperative course was uncomplicated (no bleeding or cerebrospinal fluid leakage). The limitation of inward eyeball movement was improved after operation. The pathological exam confirmed diagnosis. A Computed tomography was done at six months, revealed no evidence of the osteoma (Figure 3). The patient was still free of symptoms after 12 months.

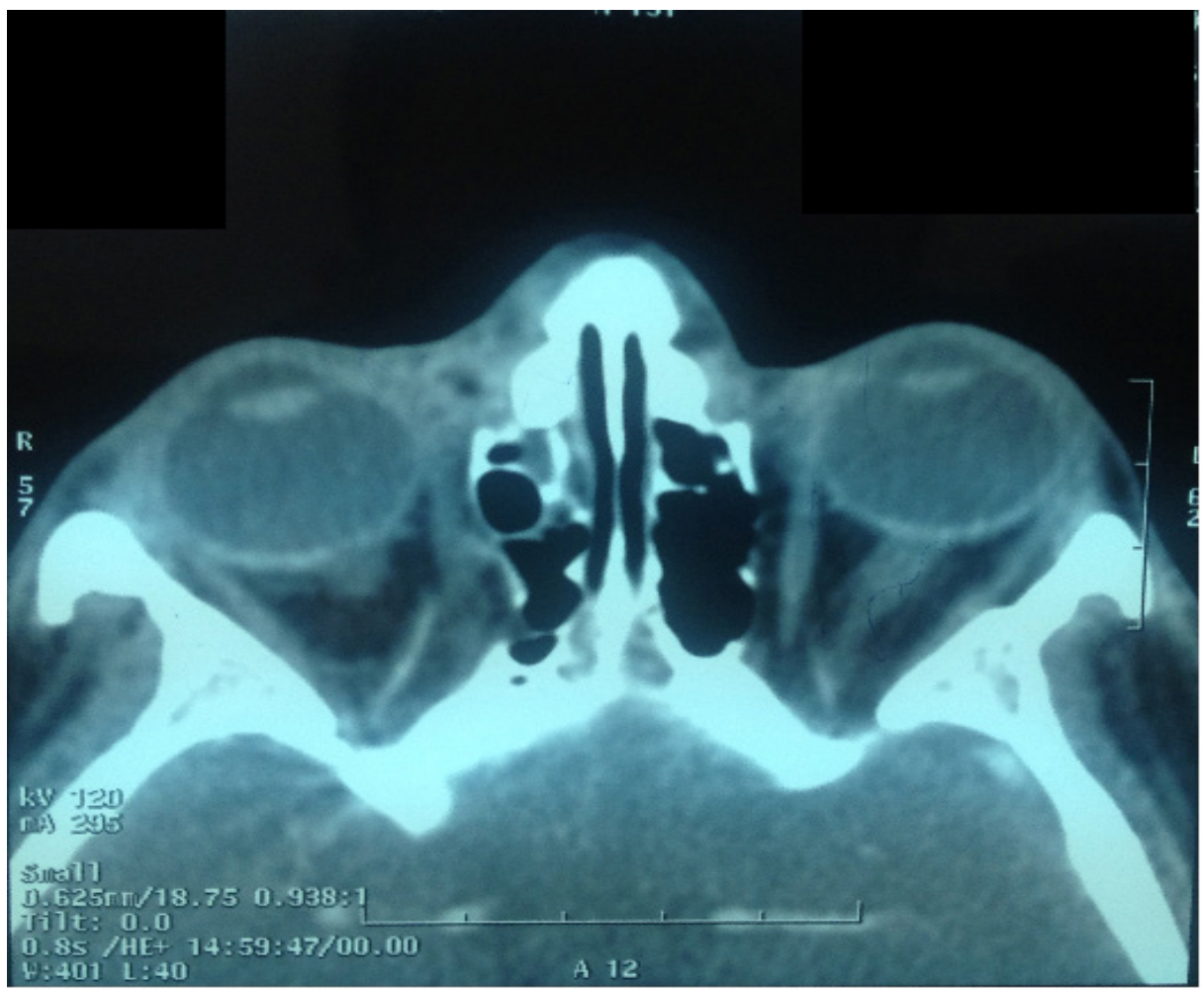

Figure 3: Postoperative axial CT scan of the patient showing total excision of the tumor (6 months after surgery) 


\section{Discussion}

The orbital osteomas are particularly rare tumors representing $0.4 \%$ to $5 \%$ of all orbital tumors [4]. The most common site is the mandible, particularly the angle, followed by the sinuses. The frontal is involved in $96 \%$, the ethmoid in $2 \%$, and the maxillary in $2 \%$. The sphenoid sinus is rarely affected, as are the long bones [5]. They grow slowly and when diameter became larger than 30 $\mathrm{mm}$, they are considered giant tumors [2]. Osteomas affect men slightly more than women [6]. The mean age is around 50 years [7]. The etiology of osteomas is controversial. Several pathogenical hypotheses are proposed: traumatic, infective and developmental origins. Sinusitis or traumas stimulate osteoblast proliferation, leading to tumor formation. The developmental theory is explained that many osteomas arise at the junction of the ethmoid and frontal sinus, a location where membranous and cartilaginous tissues meet during embryonic life [8]. Usually, orbital osteoma is asymptomatic. In patients with giant ethmoidal sinus osteomas, the ocular signs are much more common including proptosis, diplopia and hypopsia. Also, they lead to headaches; facial deformity or fatal complications [9]. A computed tomography (CT) scan is the imaging modality of choice, because CT determines the anatomic location, the extension and the dimensions of the tumor [10]. Osteoma appears like a round or oval mass, well-circumscribed, with dense bony structure [11]. The osteomas can be observed in Gardner syndrome. This autosomal dominant disorder is characterized by intestinal polyposis, osteomas, and cutaneous and soft-tissue tumors. The risk to develop colon cancer is $100 \%$ [12]. Three histological patterns are recognised: ivory osteoma, mature osteoma, and mixed osteoma (Figure 4). Ivory osteoma also known as eburnated osteoma is a dense bone lacking haversian system. Mature osteoma or osteoma spongiosum resembles to 'normal' bone, including trabecular bone often with marrow. Mixed osteoma is mixture of ivory and mature histology [13]. No malignant transformation has been reported [14]. The differential diagnosis includes fibrous dysplasia, ossifying fibroma, condensing osteitis, and osteoblastoma [15]. The surgical approaches for symptomatic osteomas of the sinuses are endoscopic surgery or external approach. In asymptomatic cases, a conservative approach is recommended with regular radiological examinations [8]. Surgical treatment is recommended for [15]:

- osteomas involving more than half of the sinus volume,

- rapidly evolving (>1 mm/year)

- Extension to the orbit or intracranial

- Location : the frontal recess and sphenoid sinus

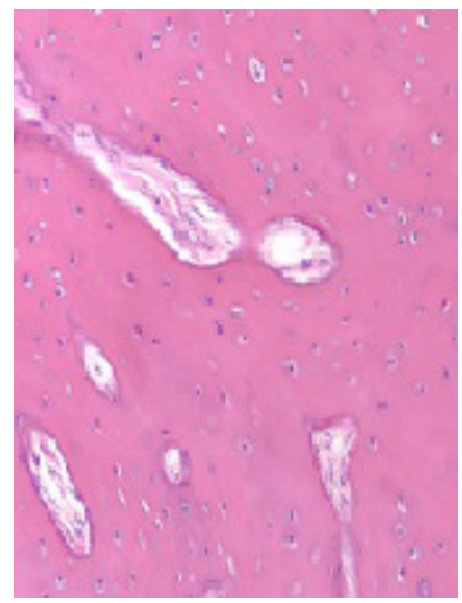

Figure 4: histological slice showing osteoma

The surgical approach to the involved sinus is generally through a lateral rhinotomy, external fronto-ethmoidectomy, osteoplastic flap, or midfacial degloving [16,17]. The subsequent herniation of the orbital content in the ethmoid should not be considered a problem because the periorbital layer is preserved, protecting the patient from diplopia, enophthalmos, or facial deformity. Then, the reconstruction of medial orbital wall is indicated only in the case of major damage to the periorbit or in extensive intraorbital dissection. No reconstruction is required when the periorbit is spared [18]. Recently, endoscopic endonasal resection of osteomas represents a new and useful approach, offering some aesthetic advantages and lowering the morbidity noted in the classical surgical technics. Nevertheless, this approach is not possible for voluminous orbital osteomas (like this case) [7].

\section{Conclusion}

Giant ethmoid osteomas are very rare. The ocular signs are prevalent. Treatment is surgical and the endoscopic approach offers more benefits. The rarity of orbital osteoma made our cases interesting to report

\section{References}

1. Osma U, Yaldiz M, Tekin M, Topcu I (2003) Giant ethmoid osteoma with orbital extension presenting with epiphora. Rhinology 41 : $122-4$.

2. Izci Y (2005) Management of the large cranial osteoma: experience with 13 adult patients. Acta Neurochir 147: 1151-5.

3. Bourgeois P, Fichten A, Louis E, Vincent C, Pertuzon B, et al. (2002) Frontal sinus osteomas: neuro-ophthalmological complications. Neurochirurgie 48: 104-8.

4. Selva D, White VA, O'Connell JX, Rootman J (2004) Primary bone tumors of the orbit. Surv Ophthalmol 49: 328-42. 
5. Gillman GS, Lampe HB, Allen LH (1997) Orbitoethmoid osteoma: case report of an uncommon presentation of an uncommon tumor. Otolaryngol Head Neck Surg 117: S218-20.

6. Lund VJ, Stammberger H, Nicolai P, Castelnuovo P, Beal T, et al. (2010) European position paper on endoscopic management of tumours of the nose, paranasal sinuses and skull base. Rhinol Suppl 22: 1-143.

7. Schick B, Steigerwald C, el Rahman el Tahan A, Draf W (2001) The role of endonasal surgery in the management of frontoethmoidal osteomas. Rhinology 39: 66-70.

8. Mansour AM, Salti H, Uwaydat S, Dakroub R, Bashshour Z (1999) Ethmoid sinus osteoma presenting as epiphora and orbital cellulitis: case report and literature review. Surv Ophthalmol 43: 413-26.

9. Erdogan N, Demir U, Songu M, Ozenler NK, Uluç E, et al. (2009) A prospective study of paranasal sinus osteomas in 1,889 cases: changing patterns of localization. Laryngoscope 119: 2355-9.

10. Trinidade A, Shakeel M, Moyes C, Ram B (2010) The evidence-based management of bilateral ethmoid osteomas: diagnosis, endoscopic resection and review of the literature. West Indian Med J 59: 188-91.

11. Miman MC, Bayindir T, Akarcay M, Erdem T, Selimoglu E (2009) Endoscopic removal technique of a huge ethmoido-orbital osteoma. J Craniofac Surg 20: 1403-6.

12. Alexander AA, Patel AA, Odland R. (2007) Paranasal sinus osteomas and Gardner's syndrome. Ann Otol Rhinol Laryngol 116: 658-62.

13. McHugh JB, Mukherji SK, Lucas DR (2009) Sino-orbital osteoma: a clinicopathologic study of 45 surgically treated cases with emphasis on tumors with osteoblastoma-like features. Arch Pathol Lab Med 133: 1587-93.

14. Nielsen GP, Rosenberg AE (2007) Update on bone forming tumors of the head and neck. Head Neck Pathol 1: 87-93.

15. Castelnuovo P, Valentini V, Giovannetti F, Bignami M, Cassoni A, et al. (2008) Osteomas of the maxillofacial district: endoscopic surgery versus open surgery.

J Craniofac Surg 19: 1446-52.

16. Hehar SS, Jones NS (1997) Fronto-ethmoid osteoma: the place of surgery. J Laryngol Otol 111: 372-5.

17. Zouloumis L, Lazaridis N, Maria P, Epivatianos A (2005) Osteoma of the ethmoidal sinus: a rare case of recurrence. Br J Oral Maxillofac Surg 43: 520-2.

18. Nicolai P, Battaglia P, Bignami M, Bolzoni Villaret A, Delù G, et al. (2008) Endoscopic surgery for malignant tumors of the sinonasal tract and adjacent skull base: a 10-year experience. Am J Rhinol 22: 308-16.

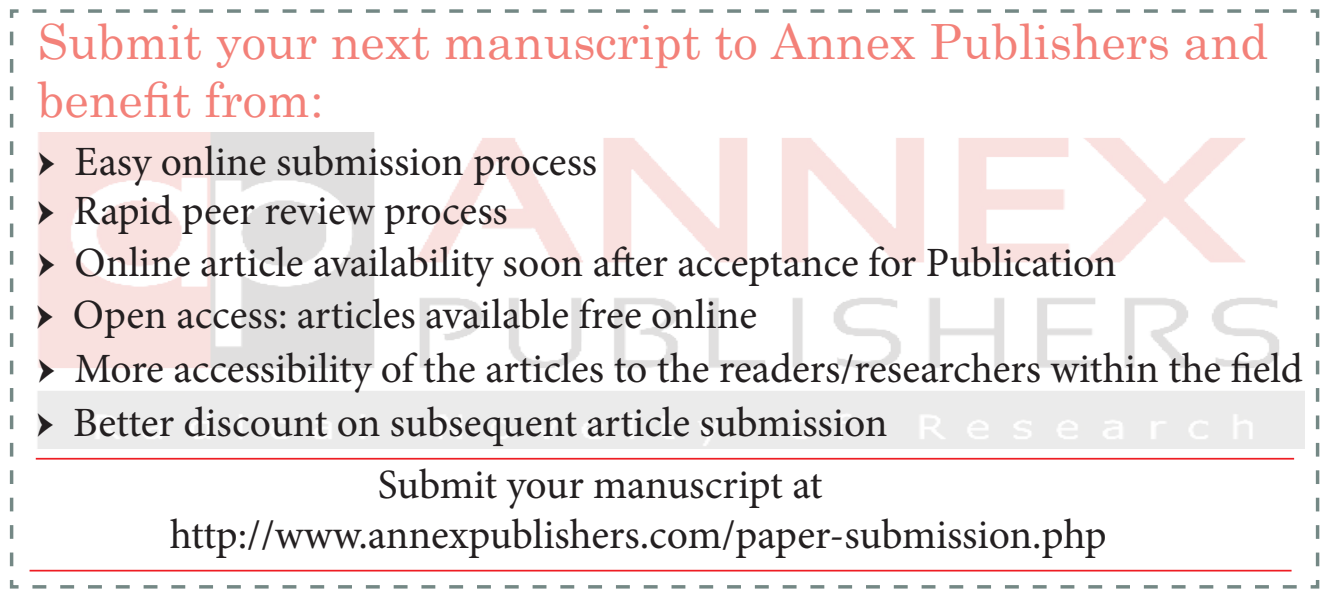

